\title{
Evaluating the prognostic value and functional roles of transcription factor AP4 in colorectal cancer
}

\author{
JIE YANG $^{1}$, JIN-PING MA ${ }^{1}$, SIYU XIAO ${ }^{2}$, XIN-HUA ZHANG $^{1}$, JIAN-BO XU ${ }^{1}$, \\ CHUANG-QI CHEN ${ }^{1}$, SHI-RONG CAI ${ }^{1}$ and YU-LONG HE ${ }^{1}$ \\ ${ }^{1}$ Department of Gastrointestinal Surgery, The First Affiliated Hospital of Sun Yat-sen University, Guangzhou, \\ Guangdong 510080; ${ }^{2}$ Department of Clinical Laboratory, The Sixth Affiliated Hospital of Sun Yat-sen University, \\ Guangzhou, Guangdong 510655, P.R. China
}

Received December 8, 2015; Accepted September 22, 2017

DOI: $10.3892 / \mathrm{ol} .2018 .8290$

\begin{abstract}
The basic helix-loop-helix transcription factor AP4 (TFAP4) gene serves an important function in the genesis and progression of tumors. However, few studies to date have defined the role of this gene in colorectal cancer (CRC). The aim of the present study was to assess the expression of TFAP4 in CRC and its impact on the prognosis of patients with CRC. In the present study, the expression of TFAP4 was detected in 30 matched pairs of fresh CRC tissues, 187 cases of clinical paraffin-embedded CRC tissues and CRC cell lines using the reverse transcriptase-quantitative polymerase chain reaction, immunohistochemistry or western blot analysis. Survival analysis was based on TFAP4 expression. The effects of TFAP4 on CRC cell function were investigated by ectopic expression or knockdown of TFAP4 in vitro. TFAP4 expression was revealed to be increased in human CRC tissues and cell lines. The overall survival (OS) time of patients with high TFAP4 expression was significantly decreased compared with patients with low TFAP4 expression $(\mathrm{P}<0.001)$. In addition, TFAP4 was revealed to be an independent prognostic factor for the OS time of patients with CRC (hazard ratio, 2.607; 95\% confidence interval, 1.469-4.627; $\mathrm{P}=0.001)$. Ectopic TFAP4 expression promoted CRC cell proliferation, migration and invasion in vitro, and the silencing of TFAP4 expression resulted in the inhibition of these events. These results demonstrated that TFAP4, which was overexpressed in CRC tissues and cell lines, increased the malignant potential of CRC cells and may serve as an indicator for poor prognosis in patients with CRC.
\end{abstract}

Correspondence to: Dr Jin-Ping Ma, Department of Gastrointestinal Surgery, The First Affiliated Hospital of Sun Yat-sen University, 58 2nd Zhongshan Road, Guangzhou, Guangdong 510080, P.R. China

E-mail: j_ma_sysu@126.com

Key words: transcription factor AP4, colorectal cancer, cell proliferation, metastasis

\section{Introduction}

Colorectal cancer (CRC) is the most predominant malignant digestive tumor and fourth leading cause of cancer-associated mortality globally (1). The rate of recurrence and metastasis varies among patients with CRC, even between those at the same stages $(2,3)$. The lack of an ideal biological marker for the prognosis of patients with advanced colorectal cancer makes individualized treatment difficult (4). Therefore, the identification of novel markers and therapeutic targets for CRC is urgently required.

Transcription factor AP4 (TFAP4; also termed AP4 or AP-4) is a ubiquitously-expressed transcription factor belonging to the basic helix-loop-helix (bHLH)/leucine zipper subgroup of bHLH proteins, which exclusively form homodimers that bind to the CAGCTG E-box motif (5-7). It has been suggested that TFAP4 is involved in multiple essential cell processes, including cell proliferation, mitotic division, cell cycle progression and apoptosis (8-10). TFAP4 target genes also include stem cell markers including LGR5, and regulators of epithelial-mesenchymal transition including Snail Family Transcriptional Repressor 1 and Epithelial cadherin (E-cadherin) $(11,12)$. In addition, TFAP4 is encoded by a c-MYC target gene and is concomitantly upregulated with c-MYC in CRC and breast cancer (11).

Previous studies have demonstrated that TFAP4 is overexpressed in breast cancer, CRC and hepatocellular carcinoma, and that it is implicated in tumor prognosis (13-15). However, few studies have analyzed the clinical and functional roles of TFAP4 in CRC. The present study investigated TFAP4 expression in CRC and evaluated its prognostic significance in 187 CRC samples. Changes in CRC cell phenotype were studied by knockdown and overexpression of TFAP4. The results indicated that TFAP4 is involved in CRC progression, and as a result, targeted inhibition of TFAP4 may represent a novel approach for the treatment of CRC.

\section{Materials and methods}

Patients. The present study included 187 patients with CRC who underwent surgery between January 2007 and January 2008 in the Department of Gastrointestinal Surgery 
at the First Affiliated Hospital of Sun Yat-sen University (Guangzhou, China). Patients were included in the present study if they had undergone a curative operation and had histologically proven colorectal cancer, and if they had not received preoperative chemotherapy and/or radiotherapy. Patients who succumbed to the disease within 3 months of surgical resection were not included. Information on clinicopathological characteristics, including age, sex, tumor size, differentiation, lymph node metastasis and liver metastasis, were retrieved from an inpatient database and are presented in Table I. Clinical and pathological classification and staging were determined according to the American Joint Committee on Cancer tumor-node-metastasis (TNM) staging system (16). Oncological outcome data were collected by telephone and the outpatient database every 3 months for the first year, every 6 months for the second to fifth year and every 12 months after 5 years. Only mortalities resulting specifically from CRC were defined as clinical endpoints.

All 187 patient specimens selected for immunohistochemical analysis were fixed in $10 \%$ formalin at room temperature for 24-48 $\mathrm{h}$ and embedded in paraffin. In addition, 30 pairs of fresh tumor tissues with matched adjacent normal tissues were stored in liquid nitrogen (at-196 $\left.{ }^{\circ} \mathrm{C}\right)$ until further use. Written informed consent was obtained from all patients for the use of their tissue samples. The Ethics Committee of the First Affiliated Hospital of Sun Yat-sen University approved the protocol of the present study.

Immunohistochemistry (IHC). Immunohistochemical staining was used to determine the expression levels of TFAP4 in CRC samples. Briefly, serial 4-mm sections were cut from paraffin-embedded blocks. For antigen retrieval, following deparaffinization and rehydration for $30 \mathrm{~min}$ at $50^{\circ} \mathrm{C}$ using a descending alcohol series (100 for $5 \mathrm{~min}, 100$ for $5 \mathrm{~min}$, 95 for $5 \mathrm{~min}, 80$ for $5 \mathrm{~min}, 70 \%$ for $5 \mathrm{~min}$, then two rinses with distilled water for $5 \mathrm{~min}$ each), sections were heated in $10 \mathrm{mmol} / \mathrm{l}$ citrate buffer $(\mathrm{pH} 6.0)$ at $125^{\circ} \mathrm{C}$ for $5 \mathrm{~min}$ and then cooled at room temperature. To block endogenous peroxidase, sections were treated in $0.3 \%$ hydrogen peroxide solution for $15 \mathrm{~min}$ at room temperature. Following incubation with goat serum (Maxim Biotech, Inc., Rockville, MD, USA) for $30 \mathrm{~min}$ at $37^{\circ} \mathrm{C}$, polyclonal rabbit TFAP4 antibodies (dilution, 1:100; cat no. SAB1404461; Aviva Systems Biology Corporation, San Diego, CA, USA) were added and incubated overnight at $4^{\circ} \mathrm{C}$ in a moist chamber. Phosphate buffer saline (PBS) was used as a negative control. The following day, sections were stained with a goat anti-rabbit IgG horseradish peroxidase-conjugated secondary antibody for $30 \mathrm{~min}$ (dilution, 1:50; cat no. 4412S; Cell Signaling Technology, Inc., Danvers, MA, USA) at room temperature and visualized using 3,3'-diaminobenzidine hydrochloride for 10-15 sec at room temperature. Finally, the sections were counterstained with Mayer's hematoxylin for $1 \mathrm{~min}$ at room temperature, dehydrated, and images were captured.

To evaluate TFAP4 expression levels, two independent pathologists assessed the images using a semi-quantitative scoring method.In detail, the intensity of immunoreactivity was scored as: 0 , negative staining; 1 , weak staining; 2 , moderate staining and 3 , strong staining. The extent of immunoreactivity was scored according to the percentage of positive staining tumor cells in each microscopic view (5 fields of view for every slice), as follows: $0,0-25 \%$ staining of tumor cells; 1 , $26-50 \%$ staining of tumor cells; $2,51-75 \%$ staining of tumor cells; and 3, 76-100\% staining of tumor cells. The total IHC score was achieved by multiplying the scores of extent and intensity. High TFAP4 expression was defined as a total score $\geq 4$, and a score $<4$ was defined as low TFAP4 expression.

Cell culture. The human colorectal cancer DLD-1, CaCo-2, HT-29, HCT-116, LS174T, LoVo and SW480 cell lines were obtained from the Cell Bank of Type Culture Collection of Chinese Academy of Sciences (Shanghai, China). The immortalized colorectal epithelial NCM460 cell line was obtained from Sun Yat-sen University. All cells were cultured in RPMI-1640 medium (Gibco; Thermo Fisher Scientific, Inc., Waltham, MA, USA) supplemented with $10 \%$ fetal bovine serum (FBS; Gibco; Thermo Fisher Scientific, Inc.) and incubated in a humidified incubator with $5 \% \mathrm{CO}_{2}$ at $37^{\circ} \mathrm{C}$.

Cell transfection with plasmids and small interfering RNAs (siRNAs). A total of three different TFAP4-specific siRNA sequences and a negative control siRNA (a scramble control produced by Guangzhou RiboBio Co.,Ltd., Guangzhou, China) were used to knockdown the expression of TFAP4 in CRC cell lines. The sequences of the three siRNAs were as follows: si-001, 5'-GACGCATGCAGAGCATCAA-3'; si-002, 5'-GGA CAAGGACGAAGGCATA-3'; and si-003, 5'-CCTCGGTCA TCAACTCTGT-3'. The expression plasmids for TFAP-4 (EX-P0109-Lv201) and the control vector (EX-NEG-Lv201) were obtained from GeneCopoeia, Inc. (Rockville, MD, USA). When cells reached $\sim 50 \%$ confluency, $50 \mu \mathrm{M}$ siRNA per well was transfected, performed using Lipofectamine 3000 reagent (Invitrogen; Thermo Fisher Scientific, Inc., Waltham, MA, USA) following the manufacturer's protocol. Transfection efficiency was confirmed by detecting the expression change of TFAP4 using western blotting and quantitative polymerase chain reaction (qPCR) as described below. Following transfection for $48 \mathrm{~h}$, the cells were harvested and moved into the 96-well culture plates, 6-well plates and transwell chambers, for use in the proliferation, migration and invasion assays, respectively.

Cell proliferation assay. Cell proliferation was examined using Cell Counting Kit-8 (Dojindo Molecular Technologies, Inc., Kumamoto, Japan) according to the manufacturer's protocol. Briefly, transfected and control cells (cells transfected with the control vector and cells transfected with the control siRNA) were seeded onto 96-well culture plates $\left(3 \times 10^{3}\right.$ cells/well $)$ and cultured for 4 days. At each 24-h interval, $10 \mu 1$ CCK-8 solution was added to each well and incubated for $2 \mathrm{~h}$ at $37^{\circ} \mathrm{C}$. Using a microplate reader (Bio-Rad Laboratories, Inc., Hercules, CA, USA), the absorbance was measured at $450 \mathrm{~nm}$.

Wound healing assay. Cells were seeded onto a 6-well plate and grown to $90 \%$ confluence. Confluent cells were then scratched using a $200-\mathrm{ml}$ pipette tip. Following rinsing three times with PBS to remove detached cells, the remaining cells were incubated in serum-deprived medium (RPMI-1640 medium with $1 \%$ FBS; Gibco; Thermo Fisher Scientific, Inc.) at $37^{\circ} \mathrm{C}$ for $48 \mathrm{~h}$. The wound status was recorded using an inverted 
Table I. Association between TFAP4 expression and the clinicopathological characteristics of patients with colorectal cancer.

\begin{tabular}{|c|c|c|c|c|}
\hline \multirow[b]{2}{*}{ Clinicopathological variable } & \multirow[b]{2}{*}{ Total, n } & \multicolumn{2}{|c|}{ TFAP4 expression, n (\%) } & \multirow[b]{2}{*}{ P-value } \\
\hline & & Low or absent & High & \\
\hline Sex & & & & 0.544 \\
\hline Male & 109 & $58(56.3)$ & $51(60.7)$ & \\
\hline Female & 78 & $45(43.7)$ & $33(39.3)$ & \\
\hline Age, years & & & & 0.383 \\
\hline$<60$ & 80 & $47(45.6)$ & $33(39.3)$ & \\
\hline$\geq 60$ & 107 & $56(54.7)$ & $51(60.7)$ & \\
\hline Location of primary tumor & & & & 0.047 \\
\hline Colon & 104 & $64(62.1)$ & $40(47.6)$ & \\
\hline Rectal & 83 & $39(37.8)$ & $44(52.4)$ & \\
\hline Tumor size, $\mathrm{cm}$ & & & & 0.632 \\
\hline$<5$ & 106 & $60(58.3)$ & $46(54.8)$ & \\
\hline$\geq 5$ & 81 & $43(41.7)$ & $38(45.2)$ & \\
\hline $\mathrm{T}$ classification & & & & 0.276 \\
\hline $\mathrm{T} 1+\mathrm{T} 2$ & 33 & $21(20.4)$ & $12(14.3)$ & \\
\hline $\mathrm{T} 3+\mathrm{T} 4$ & 154 & $82(79.6)$ & $72(85.7)$ & \\
\hline Lymph node invasion & & & & $<0.001$ \\
\hline No & 116 & $77(74.8)$ & $39(46.4)$ & \\
\hline Yes & 71 & $26(25.2)$ & $45(53.6)$ & \\
\hline Metastasis & & & & $<0.001$ \\
\hline M0 & 163 & $97(94.2)$ & $64(76.2)$ & \\
\hline M1 & 26 & $6(5.8)$ & $20(23.8)$ & \\
\hline TNM stage & & & & $<0.001$ \\
\hline I-II & 107 & $74(71.8)$ & $33(39.3)$ & \\
\hline III-IV & 80 & $29(28.2)$ & $51(60.7)$ & \\
\hline Pathological differentiation & & & & 0.024 \\
\hline Well & 14 & $12(11.7)$ & $2(2.4)$ & \\
\hline Moderate & 138 & $76(73.8)$ & $62(73.8)$ & \\
\hline Poor & 35 & $15(14.6)$ & $20(23.8)$ & \\
\hline Therapeutic strategy & & & & 0.392 \\
\hline Surgery only & 111 & $64(62.1)$ & $47(56.0)$ & \\
\hline Surgery + chemotherapy & 76 & $39(37.9)$ & $37(44.0)$ & \\
\hline Vital status (as followed up) & & & & $<0.001$ \\
\hline Alive & 124 & $83(80.6)$ & $41(48.8)$ & \\
\hline Dead & 63 & $20(19.4)$ & $43(51.2)$ & \\
\hline
\end{tabular}

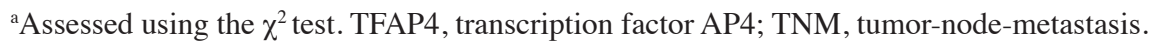

microscope at a magnification of $\mathrm{x} 40$ (Olympus Corporation, Tokyo, Japan) at 0,24 and $48 \mathrm{~h}$ after scratching. Distances covered by migrated cells were quantified via ImageJ software (version 1.48; National Institutes of Health, Bethesda, MD, USA). The experiment was performed three times.

Migration and invasion assay. Cell invasion and migratory potential were evaluated in 24-well plates using Transwell chambers $(8 \mu \mathrm{m}$ pore membrane; BD Biosciences, Franklin Lakes, NJ, USA). For the migration assay, cells $\left(5 \times 10^{4}\right)$ were seeded into the upper chamber. For the invasion assay,
$1 \times 10^{5}$ cells were seeded into the upper chamber, where the membrane was covered with matrix gel (BD Biosciences). To create a chemoattractant, cells were suspended in $100 \mu \mathrm{l}$ serum-free RPMI-1640 medium in the upper chamber, whereas the lower chamber contained $500 \mu \mathrm{l}$ RPMI-1640 with $10 \% \mathrm{FBS}$. After $20 \mathrm{~h}$ of incubation at $37^{\circ} \mathrm{C}$ for the migration assay and $24 \mathrm{~h}$ for the invasion assay, the membranes were fixed with $4 \%$ paraformaldehyde for $20 \mathrm{~min}$ at room temperature and stained with $0.1 \%$ crystal violet at room temperature for $20 \mathrm{~min}$. The cells on the upper surface were removed using a cotton swab. The number of invaded and migrated cells was 
quantified by counting five different fields of view under a light microscope at a magnification of x200.

Western blot analysis. Human CRC tissues and cells were lysed in ice-cold radioimmunoprecipitation assay lysis buffer (Beyotime Institute of Biotechnology, Haimen, China) with added protease and phosphatase inhibitors (Beyotime Institute of Biotechnology). Following removal of the cell debris by centrifugation $\left(13,000 \mathrm{x} \mathrm{g}\right.$ at $4^{\circ} \mathrm{C}$ for $20 \mathrm{~min}$ ), the protein concentration was measured using the Bicinchoninic Acid Protein Assay kit (Beyotime Institute of Biotechnology). Equal amounts of protein $(20 \mu \mathrm{g})$ were separated on $10 \%$ SDS-PAGE gels and transferred to polyvinylidene fluoride membranes (EMD Millipore, Billerica, MA, USA). Following blocking with 5\% bovine serum albumin (Beyotime Institute of Biotechnology) for $1 \mathrm{~h}$ at room temperature, the membranes were incubated overnight at $4^{\circ} \mathrm{C}$ with the following antibodies: TFAP4 (dilution, 1:1,000; cat no. SAB1404461; Sigma-Aldrich; Merck KGaA, Darmstadt, Germany) and $\beta$-tubulin (dilution, 1:10,000; cat no. 86298; Cell Signaling Technology, Inc.). Following washing with TBS containing Tween-20, the membranes were incubated with secondary antibodies [dilution, 1:5,000; goat anti-rabbit horseradish peroxidase (HRP)-conjugated secondary antibody, cat no. 7074 and goat anti-mouse HRP-conjugated secondary antibody, cat no. 7076; Cell Signaling Technology] at room temperature for $1 \mathrm{~h}$. Finally, proteins on the membranes were visualized using enhanced chemiluminescence reagents (EMD Millipore) in the ImageQuant Las4000mini detection system (GE Healthcare Bio-Sciences, Pittsburgh, PA, USA).

$R N A$ extraction and reverse transcription- $q P C R(R T-q P C R)$. Total RNA was isolated from the cells or tissues using TRIzol reagent (Takara Bio, Inc., Otsu, Japan) according to the manufacturer's protocol, and $500 \mathrm{ng}$ RNA was reverse-transcribed into cDNA using the Prime Script RT Master Mix (Takara Bio, Inc.) according to the manufacturer's protocol. RT-qPCR was performed with the resultant cDNA as a template using the SYBR Premix Ex Taq kit (RNaseH Plus; Takara Bio, Inc.) according to the manufacturer's protocol in the Bio-Rad CFX96 cycler (Bio-Rad Laboratories, Inc.) under the following conditions: $95^{\circ} \mathrm{C}$ for $30 \mathrm{sec}, 40$ cycles of $95^{\circ} \mathrm{C}$ for $3 \mathrm{sec}, 60^{\circ} \mathrm{C}$ for $30 \mathrm{sec}$ and $72^{\circ} \mathrm{C}$ for $50 \mathrm{sec}$. PCR reactions were performed in triplicate and repeated three times. The relative level of TFAP4 mRNA was calculated using the $2^{-\Delta \Delta \mathrm{Cq}}$ method (17) with normalization to GAPDH. Primers were designed as follows: TFAP4 forward, 5'-GAGCCAGCCTGGGATTGTC-3'; TFAP4 reverse, 5'-GTG CTTAAAGGAGAAAGAAGAAAACC-3'; GAPDH forward, 5'-TGTTGCCATCAATGACCCCTT-3'; and GAPDH reverse, 5'-CTCCACGACGTACTCAGCG-3'.

Statistical analysis. All data were analyzed using SPSS 19.0 statistical software (IBM SPSS, Armonk, NY, USA). The data were presented as the mean \pm the standard deviation. The association between TFAP4 expression and clinicopathological parameters was analyzed using the $\chi^{2}$ test. Survival analysis was performed using the Kaplan-Meier method and the log-rank test. The significant prognostic factors in the univariate survival analysis were subsequently investigated with Cox's proportional hazards model for multivariate survival analysis. Other comparisons between two groups were made using Student's t-tests, with one-way analysis of variance (followed by Tukey's post hoc test) used for comparisons between more than two groups. $\mathrm{P}<0.05$ was considered to indicate a statistically significant difference.

\section{Results}

TFAP4 expression and prognosis in CRC. To investigate the function of TFAP4 in CRC, TFAP4 expression was examined in human CRC tissue and cell lines. RT-qPCR experiments revealed that TFAP4 mRNA expression was increased in all seven CRC cell lines compared with the immortalized colorectal epithelial NCM460 cell line (Fig. 1A). Western blotting revealed similar results in terms of protein TFAP4 expression (Fig. 1B). In CRC tissues, the TFAP4 mRNA expression level was 4.3-fold higher than that of adjacent normal tissues (Fig. 1C). Western blotting results also revealed that with the exception of in lane number 3, TFAP4 protein expression levels were markedly increased in the tumor tissues compared with matched adjacent normal tissues (Fig. 1D).

Next, TFAP4 protein expression was examined in 187 CRC tissues by IHC. Representative images of cytoplasmic and nuclear TFAP4 protein expression in the tumor cells are presented in Fig. 2A. The positive expression rate was $76.5 \%$ (143 of 187). To evaluate the association between TFAP4 expression and clinicopathological parameters, patients were divided into two groups based on the aforementioned IHC score assessment system. The results revealed that high TFAP4 expression was positively associated with TNM stage $(\mathrm{P}<0.001)$, lymph node invasion $(\mathrm{P}<0.001)$, liver metastasis $(\mathrm{P}<0.001)$ and differentiation $(\mathrm{P}=0.024)$. More details are presented in Table I.

Since TFAP4 overexpression was associated with CRC progression, the present study investigated whether high TFAP4 expression was a prognostic factor in patients with CRC. Kaplan-Meier survival analysis demonstrated that high TFAP4 expression was significantly associated with poor overall survival (OS), and was also a significant prognostic factor within stage I-II and stage III-IV patients $(\mathrm{P}<0.001$; Fig. 2B-D). In addition, univariate and multivariate Cox regression analysis was performed to examine whether TFAP4 expression was an independent prognostic factor. Univariate analysis revealed that high TFAP4 expression, degree of differentiation, lymph node metastasis, liver metastasis and TNM stage were prognostic factors for OS time. However, in the multivariate Cox regression analysis, only liver metastasis and high TFAP4 expression were associated with poor OS (Table II). The present data demonstrated that high TFAP4 expression was an independent prognostic factor for patients with CRC (hazard ratio $=2.607 ; 95 \%$ confidence interval, 1.469-4.627; $\mathrm{P}<0.001)$.

TFAP4 promotes colorectal cancer cell proliferation, migration and invasion in vitro. To determine the function of TFAP4 in CRC cells, cell proliferation, motility and invasion assays were performed to evaluate the effect of TFAP4 overexpression or knockdown on CRC cell lines in vitro. The SW480 
A

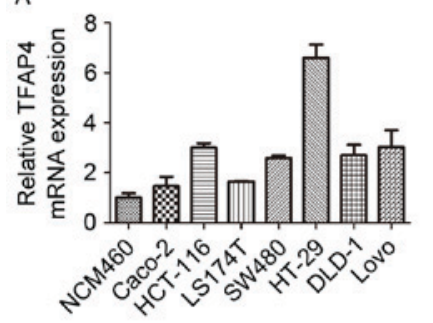

C

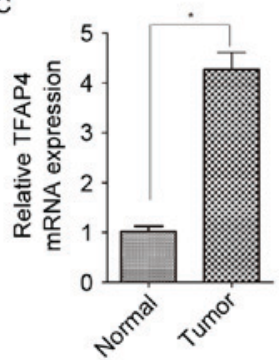

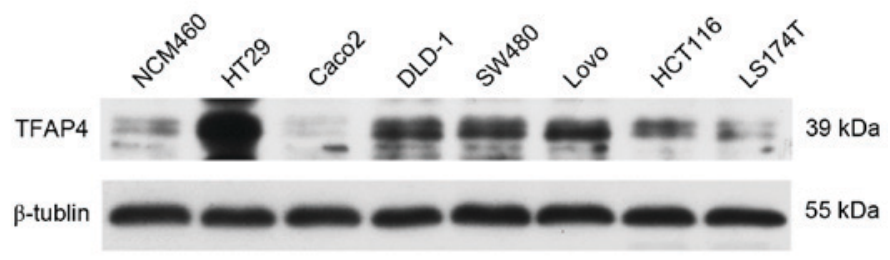

D

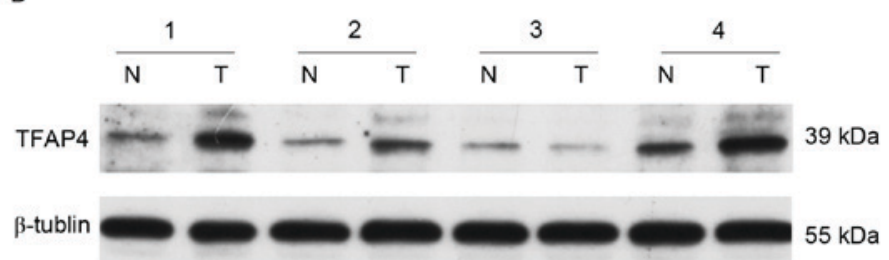

Figure 1. TFAP4 overexpression in CRC cells and tissues, as assessed using reverse transcription-quantitative polymerase chain reaction analysis and western blotting. (A) TFAP4 mRNA expression in CRC cell lines was higher than in a normal colonic epithelial cell line. (B) Expression of TFAP4 was increased in cancer tissues. The TFAP4 (C) mRNA and (D) protein expression levels of colorectal cancer tissues were higher than that of matched adjacent non-cancerous tissues ( $(\mathrm{P}<0.001)$. Representative gel images are presented. TFAP4, transcription factor AP4.

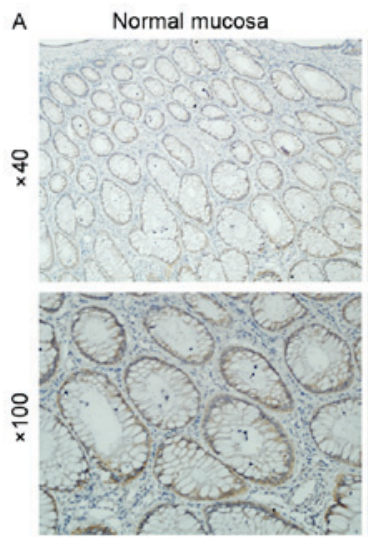

B

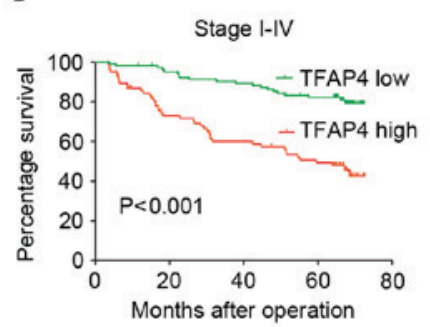

High differentiation
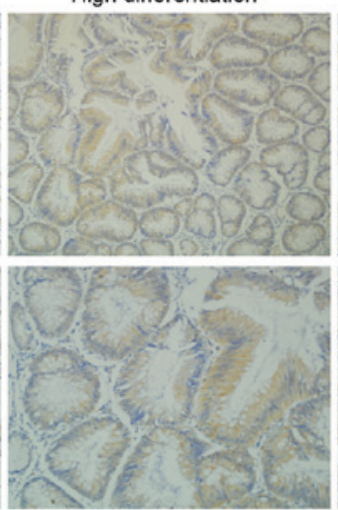

Moderate differentiation

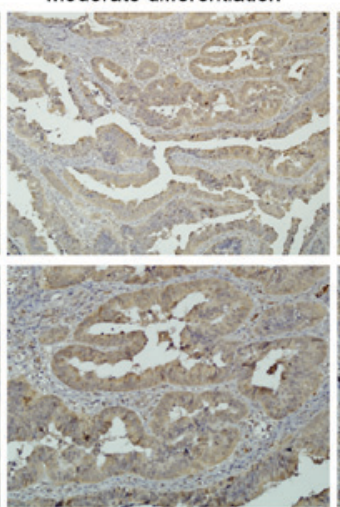

Poor differentiation

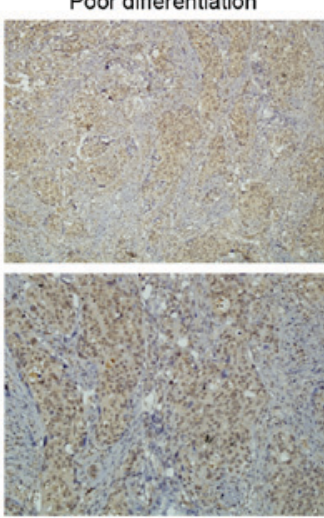

$\mathrm{C}$

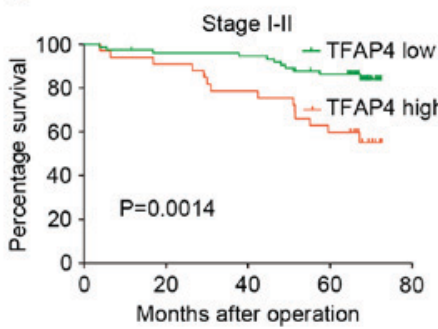

D

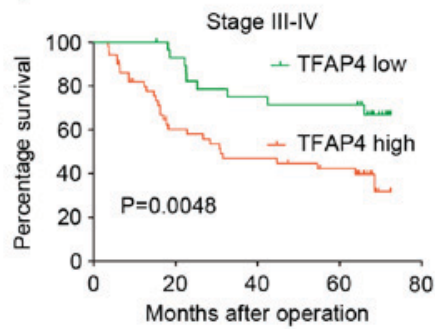

Figure 2. Prognostic significance of TFAP4 expression in patients with colorectal cancer. (A) Representative images of TFAP4 expression in normal tissue, high differentiation, moderate differentiation and low differentiation. Kaplan-Meier analysis of overall survival based on TFAP4 expression in (B) all patients, (C) stage I-II patients and (D) stage III-IV patients ( $\mathrm{P}<0.001)$. TFAP4, transcription factor AP4.

cell line, which exhibits relatively low TFAP4 expression, was transfected with a TFAP4-expressing plasmid (V-TFAP4). To knockdown TFAP4, the HT29 cell line, which expresses a relatively high level of TFAP4, was transfected with specific siRNAs. RT-PCR and western blot analysis demonstrated that TFAP4 expression was reduced by siRNA and increased by cDNA transfection, respectively (Fig. 3). The results indicated that si-002 was the most effective sequence in terms of TFAP4 inhibition. Therefore, si-002 was used for subsequent experiments, and the negative control siRNA (50 nM) was used as a control.

In cell proliferation assays, overexpression of TFAP4 was revealed to significantly promote proliferation, while downregulation of TFAP4 inhibited CRC cell proliferation 
Table II. Univariate and multivariate analyses of various potential prognostic factors in patients with colorectal cancer.

\begin{tabular}{|c|c|c|c|c|c|}
\hline \multirow[b]{2}{*}{ Factors } & \multirow[b]{2}{*}{ Cases, $\mathrm{n}$} & \multicolumn{2}{|c|}{ Univariate analysis } & \multicolumn{2}{|c|}{ Multivariate analysis } \\
\hline & & $\mathrm{HR}(95 \% \mathrm{CI})$ & P-value & $\mathrm{HR}(95 \% \mathrm{CI})$ & P-value \\
\hline Age, years & & $1.668(0.981-2.836)$ & 0.059 & $1.552(0.875-2.783)$ & 0.140 \\
\hline$<60$ & 80 & & & & \\
\hline$\geq 60$ & 107 & & & & \\
\hline Sex & & $1.373(0.818-2.304)$ & 0.231 & $1.486(0.864-2.557)$ & 0.152 \\
\hline Male & 109 & & & & \\
\hline Female & 78 & & & & \\
\hline Tumor size, $\mathrm{cm}$ & & $1.409(0.860-2.311)$ & 0.174 & $1.105(0.658-1.858)$ & 0.705 \\
\hline$<5$ & 106 & & & & \\
\hline$\geq 5$ & 81 & & & & \\
\hline Therapeutic strategy & & $0.942(0.568-1.560)$ & 0.816 & $0.770(0.433-1.370)$ & 0.374 \\
\hline Sur & 111 & & & & \\
\hline Sur + chemo & 76 & & & & \\
\hline Differentiation & & $0.161(0.022-1.161)$ & 0.070 & $0.334(0.044-2.528)$ & 0.288 \\
\hline Well & 14 & & & & \\
\hline Moderate/poor & 173 & & & & \\
\hline Depth of invasion & & $1.581(0.753-3.320)$ & 0.226 & $1.121(0.511-2.460)$ & 0.775 \\
\hline $\mathrm{T} 1-\mathrm{T} 2$ & 33 & & & & \\
\hline $\mathrm{T} 3-\mathrm{T} 4$ & 154 & & & & \\
\hline Lymph node invasion & & $2.343(1.427-3.848)$ & 0.001 & $1.594(0.526-4.828)$ & 0.410 \\
\hline Present & 71 & & & & \\
\hline Absent & 116 & & & & \\
\hline Metastasis & & $5.957(3.425-10.360)$ & $<0.001$ & $3.833(1.868-7.863)$ & $<0.001$ \\
\hline Present & 26 & & & & \\
\hline Absent & 163 & & & & \\
\hline TNM stage & & $2.880(1.734-4.782)$ & $<0.001$ & $1.060(0.315-3.569)$ & 0.925 \\
\hline I-II & 107 & & & & \\
\hline III-IV & 80 & & & & \\
\hline TFAP4 expression & & $3.703(2.174-6.306)$ & $<0.001$ & $2.607(1.469-4.627)$ & 0.001 \\
\hline High & 84 & & & & \\
\hline Low & 103 & & & & \\
\hline
\end{tabular}

HR, hazard ratio; CI, confidence interval; Sur, surgery only; Sur + chemo, surgery plus adjuvant chemotherapy; TNM, tumor-node-metastasis; TFAP4, transcription factor AP4.

(P<0.05; Fig. 4). Compared with control cells, overexpression of TFAP4 stimulated increased migration and invasion, whereas knockdown had an inhibitory effect on these phenomena $(\mathrm{P}<0.05$; Figs. 5-7). In detail, in the wound healing assays, knockdown of TFAP4 repressed the cell motility of CRC cells, but overexpression of TFAP4 improved their motility (Fig. 5). Transwell migration assays revealed that ectopic expression of TFAP4 stimulated tumor cell migration, and that the number of migrated cells was reduced following TFAP4 knockdown (Fig. 6). Similarly, the invasive ability was improved in TFAP4-overexpressed CRC cells; however, TFAP4 knockdown in CRC cells indicated the opposite effect (Fig. 7). Taken together, the present data demonstrated that TFAP4 promoted $\mathrm{CRC}$ proliferation, migration and invasion in vitro.

\section{Discussion}

In the present study, high expression of TFAP4 in CRC cell lines and specimens compared with normal cells and tissue was observed. Multivariate survival analysis revealed that the TFAP4 expression level in CRC was an independent prognostic factor. Functional analysis demonstrated that TFAP4 contributed to CRC cell proliferation, migration and invasion.

TFAP4 was initially identified as a cellular protein that binds to the simian virus 40 enhancer and activates viral late gene transcription (18). TFAP4 controls transcriptional networks during cellular differentiation through homodimer formation and binding to the symmetrical DNA sequence, CAGCTG (5). High TFAP4 expression has been reported in CRC, breast cancer 
A

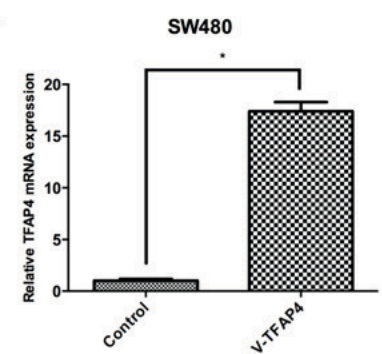

c

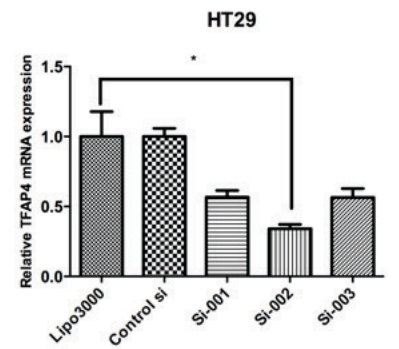

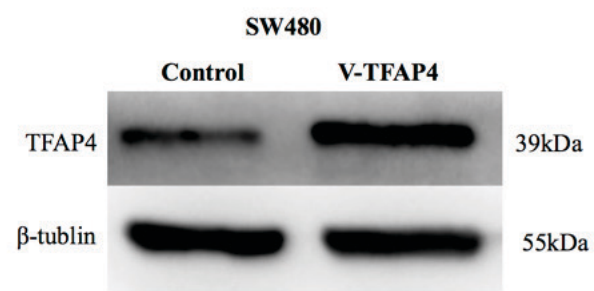

D

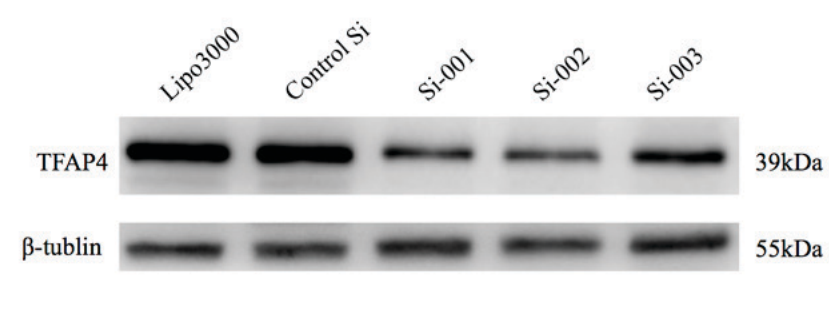

Figure 3. Transfection efficiency was confirmed by RT-qPCR and western blot analysis. The (A) mRNA and (B) protein levels of TFAP4 were increased following overexpression of TFAP4 in SW480 cells. (C) RT-qPCR and (D) western blot analysis revealed that si-002 was the most efficient siRNA for TFAP4 inhibition. " $\mathrm{P}<0.05$. RT-qPCR, reverse transcription-quantitative polymerase chain reaction; si, small interfering; TFAP4, transcription factor AP4.

HT29

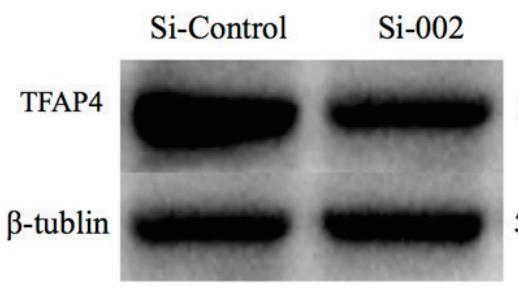

HT29

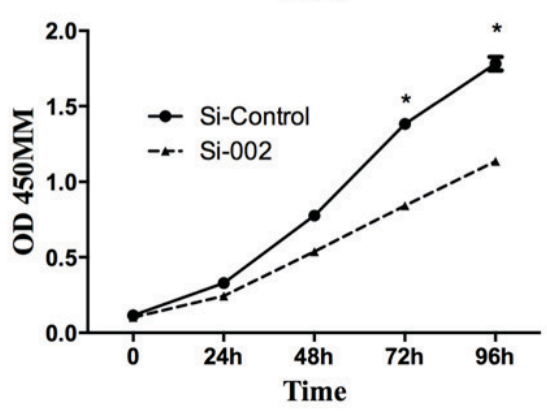

SW480
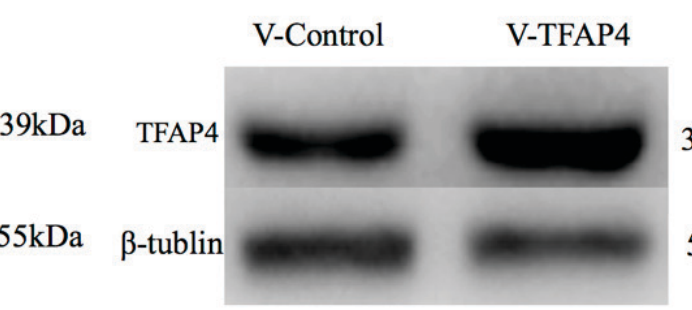

$39 \mathrm{kDa}$

$55 \mathrm{kDa}$

Figure 4. TFAP4 promotes cell proliferation in colorectal cancer cell lines. TFAP4 protein level was increased following overexpression of TFAP4 in SW480 cells and decreased following knockdown of TFAP4 in HT-29 cells. Cell Counting Kit- 8 assays revealed that overexpressed TFAP4 stimulated tumor cell growth, whereas knockdown of TFAP4 inhibited cell growth ability. "P<0.05 vs. 0 h. TFAP4, transcription factor AP4; si, small interfering; OD, optical density.

and hepatocellular carcinoma (13-15). These results also indicate that TFAP4 overexpression is associated with a worse prognosis.

Previous studies have established a functional role for TFAP4 in several crucial aspects of tumor progression, including proliferation, apoptosis $(9,11,12,19)$, transformation (10), invasion, metastasis (12) and chemoresistance $(13,20)$, indicating that TFAP4 is potentially involved in tumorigenesis. Loss of p21 expression is associated with the promotion of neoplasia, tumorigenesis and progression in CRC (21). The p21 gene encodes a cell cycle-dependent kinase inhibitor, which is induced by p53 and numerous other anti-proliferative factors (22). Jackstadt et al $(9,10)$ reported that TFAP4 promotes cell proliferation via direct repression of $\mathrm{p} 21$ by occupying four CAGCTG motifs in the basic region of the $\mathrm{p} 21$ promoter. Since TFAP4 is a c-MYC target gene and is upregulated in colorectal tumors, and this upregulation is a hallmark of CRC (23), it was hypothesized that TFAP4 may be involved in tumor progression. In the present study, knockdown of endogenous TFAP4 inhibited CRC cell proliferation, whereas ectopic expression of TFAP4 enhanced these capacities. These results are consistent 

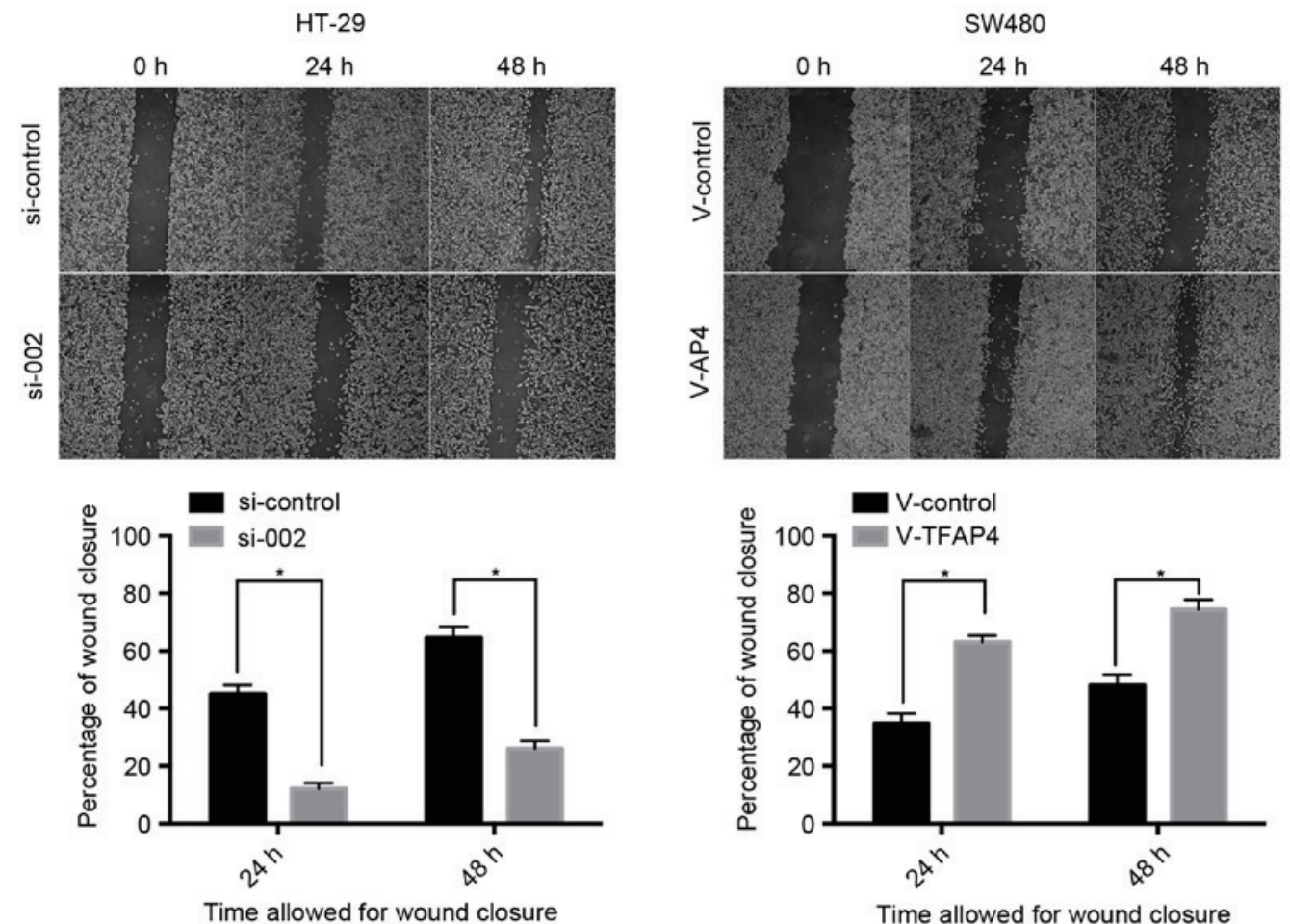

Figure 5. TFAP4 promotes cell motility in colorectal cancer cell lines. Compared with control cells, knockdown of TFAP4 repressed the cell motility of HT-29 cells. Overexpression of TFAP4 stimulated cell motility in SW480 cells compared with that of control cells. Images presented at magnification, $\mathrm{x} 40 .{ }^{*} \mathrm{P}<0.05$, with comparisons indicated by lines. TFAP4, transcription factor AP4; si, small interfering.

HT-29
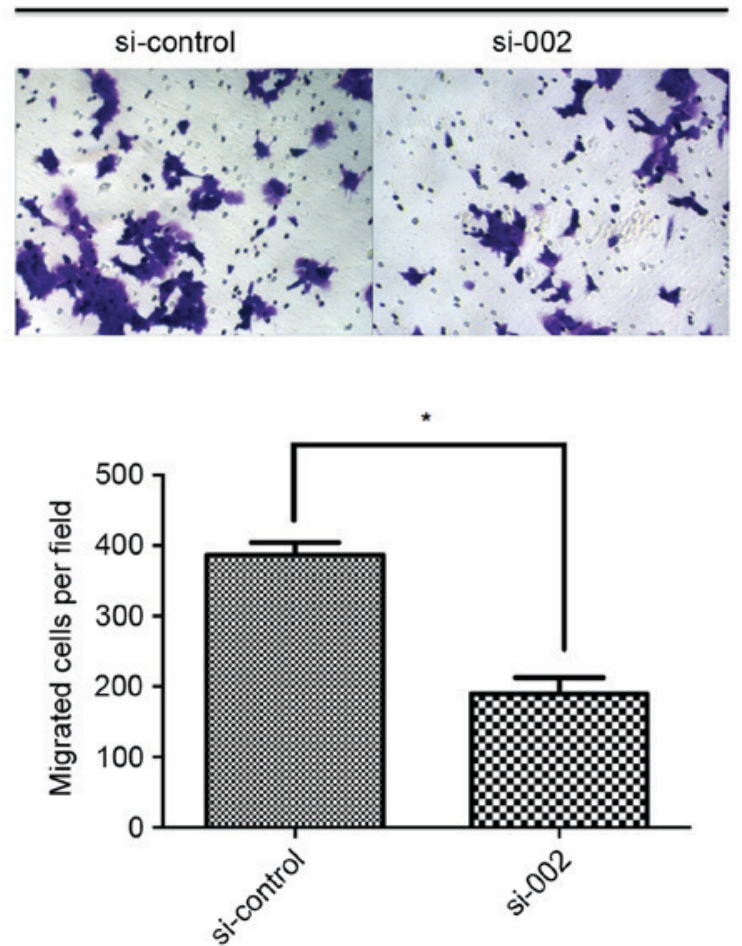

SW480
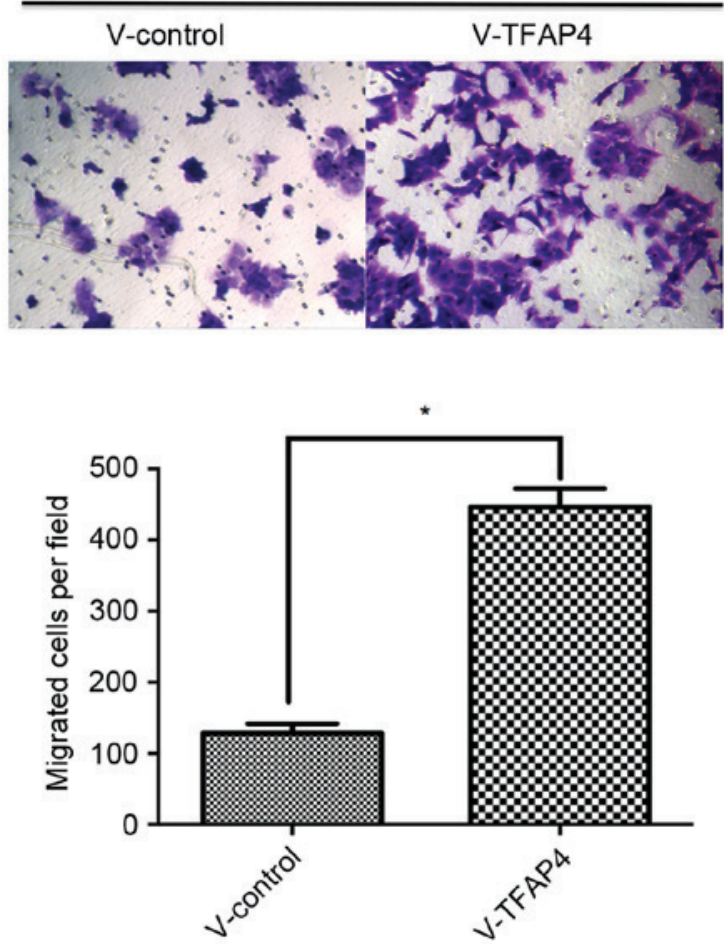

Figure 6. TFAP4 promotes cell migration in colorectal cancer cell lines. Transwell migration assays revealed that ectopic expression of TFAP4 stimulated tumor cell migration, whereas knockdown of TFAP4 had the opposite effect. Images presented at magnification, $\mathrm{x} 100 .{ }^{*} \mathrm{P}<0.05$, with comparisons indicated by lines. TFAP4, transcription factor AP4; si, small interfering.

with previous studies $(12,14)$ highlighting the involvement of TFAP4 in the progression of CRC.
In gastrointestinal adenocarcinoma, TFAP4 promotes cell proliferation by affecting key regulators of the cell cycle $(9,20)$. 
HT-29
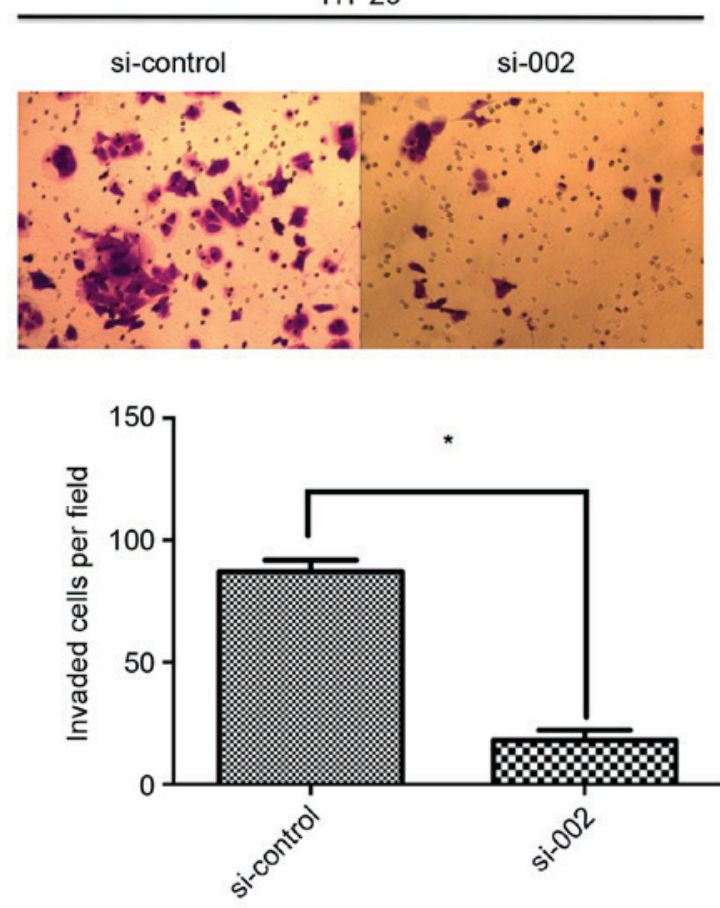

SW480
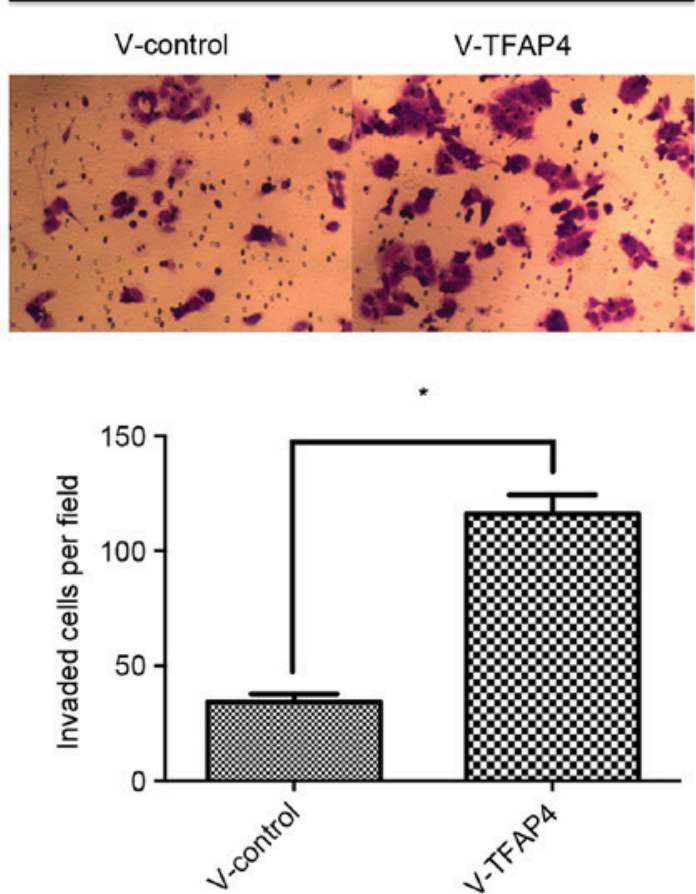

Figure 7. TFAP4 promotes cell invasion in colorectal cancer cell lines. Overexpression of TFAP4 induced the invasion of more tumor cells through the membrane. The number of invaded cells was reduced following TFAP4 knockdown. Images presented at magnification, x100. "P<0.05, with comparisons indicated by lines. TFAP4, transcription factor AP4; si, small interfering.

In breast cancer, TFAP4 suppresses cell proliferation by inducing the c-Jun N-terminal kinase/TFAP4/protein tyrosine phosphatase, non-receptor type 6 signaling pathway (13). The contradictory effect of TFAP4 in colorectal cancer and breast cancer suggests that TFAP4 performs a differential role in cell proliferation and that TFAP4-activated signaling pathways may be tumor-specific. The present study demonstrated that TFAP4 promotes the proliferation of CRC cells. The results were consistent with those of previous studies, demonstrating that TFAP4 serves an essential function in tumor cell proliferation $(9,20)$.

Jackstadt et al (12) reported that TFAP4 is a novel regulator of the epithelial-mesenchymal transition (EMT), which contributes to the metastatic processes in colorectal cancer. TFAP4 directly represses E-cadherin via a non-canonical TFAP4-binding motif and induces neural-cadherin, the process of which is a hallmark of the EMT (12). Consistent with the study by Jackstadt et al (12), the present study revealed that TFAP4 expression is also positively associated with liver metastasis, and that TFAP4 overexpression promotes cell migration and invasion in vitro. These results indicated that TFAP4 activation may also induce EMT and enhance the migration and invasion of CRC cells. However, additional studies on the molecular mechanisms underlying these events are required.

In summary, consistent with the function of TFAP4 in numerous different aspects of tumor malignancy, the present study demonstrated that TFAP4 is overexpressed in colorectal cancer and that TFAP4 is associated with poor clinical outcome in patients with CRC. In addition, TFAP4 is an independent prognostic factor for the OS of patients with CRC. Overexpression of TFAP4 promotes cell proliferation, migration and invasion. Future studies should focus on the identification of TFAP4-interacting proteins and the validation of the potential effectiveness of TFAP4 as a target for intervening with CRC progression.

\section{Acknowledgements}

Not applicable.

\section{Funding}

The present study was supported by the Science and Technology Planning Project of Guangdong Province Daya Bay (grant no. 2013A01015).

\section{Availability of data and materials}

The datasets generated and analyzed in the present study are included in this published article.

\section{Authors' contributions}

JY designed the procedure and study, analyzed the data and wrote the report. JPM and XHZ assisted design of study protocol and critically revised the report. JBX, CQC, SRC and YLH performed the operations and perioperative care of the patient and revised the report. SX provided assistance during the experiments of RT-PCR and the revision of the manuscript.

\section{Ethics approval and consent to participate}

Written informed consent was obtained from all patients for the use of their tissue samples. The Ethics Committee of the 
First Affiliated Hospital of Sun Yat-sen University approved the protocol of the present study.

\section{Consent for publication}

The study participants provided consent for the data to be published.

\section{Competing interests}

The authors declare that they have no competing interests.

\section{References}

1. Jemal A, Bray F, Center MM, Ferlay J, Ward E and Forman D: Global cancer statistics. CA Cancer J Clin 61: 69-90, 2011.

2. Pritchard CC and Grady WM: Colorectal cancer molecular biology moves into clinical practice. Gut 60: 116-129, 2011.

3. Augestad KM, Bakaki PM, Rose J, Crawshaw BP, Lindsetmo RO, Dørum LM, Koroukian SM and Delaney CP: Metastatic spread pattern after curative colorectal cancer surgery. A retrospective, longitudinal analysis. Cancer Epidemiol 39: 734-744, 2015.

4. Luo HY and Xu RH: Predictive and prognostic biomarkers with therapeutic targets in advanced colorectal cancer. World J Gastroenterol 20: 3858-3874, 2014.

5. Hu YF, Lüscher B, Admon A, Mermod N and Tjian R: Transcription factor AP-4 contains multiple dimerization domains that regulate dimer specificity. Genes Dev 4: 1741-1752, 1990.

6. Atchley WR and Fitch WM: A natural classification of the basic helix-loop-helix class of transcription factors. Proc Natl Acad Sci USA 94: 5172-5176, 1997.

7. Jung $\mathrm{P}$ and Hermeking H: The c-MYC-AP4-p21 cascade. Cell Cycle 8: 982-989, 2009.

8. Kim MY, Jeong BC, Lee JH, Kee HJ, Kook H, Kim NS, Kim YH, Kim JK, Ahn KY and Kim KK: A repressor complex, AP4 transcription factor and geminin, negatively regulates expression of target genes in nonneuronal cells. Proc Natl Acad Sci USA 103: 13074-13079, 2006.

9. Jackstadt R and Hermeking H: AP4 is required for mitogen- and c-MYC-induced cell cycle progression. Oncotarget 5: 7316-7327, 2014.

10. Jackstadt R, Jung P and Hermeking H: AP4 directly downregulates p16 and p21 to suppress senescence and mediate transformation. Cell Death Dis 4: e775, 2013.

11. Jung P, Menssen A, Mayr D and Hermeking H: AP4 encodes a c-MYC-inducible repressor of p21. Proc Natl Acad Sci USA 105: 15046-15051, 2008

12. Jackstadt R, Röh S, Neumann J, Jung P, Hoffmann R, Horst D, Berens C, Bornkamm GW, Kirchner T, Menssen A and Hermeking H: AP4 is a mediator of epithelial-mesenchymal transition and metastasis in colorectal cancer. J Exp Med 210: 1331-1350, 2013.
13. Amin S, Kumar A, Nilchi L, Wright K and Kozlowski M: Breast cancer cells proliferation is regulated by tyrosine phosphatase SHP1 through c-jun N-terminal kinase and cooperative induction of RFX-1 and AP-4 transcription factors. Mol Cancer Res 9: 1112-1115, 2011.

14. Xinghua L, Bo Z, Yan G, Lei W, Changyao W, Qi L, Lin Y, Kaixiong T, Guobin W and Jianying C: The overexpression of AP-4 as a prognostic indicator for colorectal carcinoma. Med Oncol 29: 871-877, 2012.

15. Hu BS, Zhao G, Yu HF, Chen K, Dong JH and Tan JW: High expression of AP-4 predicts poor prognosis for hepatocellular carcinoma after curative hepatectomy. Tumour Biol 34: 271-276, 2013.

16. Edge SB, Byrd SR, Compton CC, et al, (eds): AJCC cancer staging manual. 7th edition Springer-Verlag; New York (NY), pp143-164, 2010.

17. Livak KJ and Schmittgen TD: Analysis of relative gene expression data using real-time quantitative PCR and the 2(-Delta Delta C(T)) method. Methods 25: 402-408, 2001.

18. Mermod N, Williams TJ and Tjian R: Enhancer binding factors AP-4 and AP-1 act in concert to activate SV40 late transcription in vitro. Nature 332: 557-561, 1988 .

19. Tsujimoto K, Ono T, Sato M, Nishida T, Oguma $T$ and Tadakuma T: Regulation of the expression of caspase- 9 by the transcription factor activator protein- 4 in glucocorticoid-induced apoptosis. J Biol Chem 280: 27638-27644, 2005.

20. Liu X, Zhang B, Guo Y, Liang Q, Wu C, Wu L, Tao K, Wang G and Chen J: Down-regulation of AP-4 inhibits proliferation, induces cell cycle arrest and promotes apoptosis in human colorectal cancer cells. PLoS One 7: e37096, 2012.

21. Zirbes TK, Baldus SE, Moenig SP, Nolden S, Kunze D, Shafizadeh ST, Schneider PM, Thiele J, Hoelscher AH and Dienes HP: Prognostic impact of p21/waf1/cip1 in colorectal cancer. Int J Cancer 89: 14-18, 2000.

22. Bunz F, Dutriaux A, Lengauer C, Waldman T, Zhou S, Brown JP, Sedivy JM, Kinzler KW and Vogelstein B: Requirement for p53 and p21 to sustain G2 arrest after DNA damage. Science 282: 1497-1501, 1998

23. Cancer Genome Atlas Network; Muzny DM, Bainbridge MN, Chang K, Dinh HH, Drummond JA, Fowler G, Kovar CL, Lewis L, Morgan MB, et al: Comprehensive molecular characterization of human colon and rectal cancer. Nature 487: 330-337, 2012.

This work is licensed under a Creative Commons Attribution-NonCommercial-NoDerivatives 4.0 International (CC BY-NC-ND 4.0) License. 